\title{
An Analysis of Noni (Morinda citrifolia) Extract Gel to Increase the Number of Macrophage and Angiogenesis in Mandibles Socket After Tooth Extraction of Guinea Pigs
}

\author{
${ }^{1}$ Mochammad Taha Ma'ruf, ${ }^{1}$ Putu Sulistiawati Dewi, ${ }^{2}$ Ria Koesoemawati and \\ ${ }^{2}$ Dewa Made Wedagama \\ ${ }^{1}$ Department of Oral and Maxillofacial Surgery, Faculty of Dentistry, \\ Mahasaraswati University of Denpasar, Denpasar, Indonesia \\ ${ }^{2}$ Department of Biomedical Science, Faculty of Dentistry, \\ Mahasaraswati University of Denpasar, Denpasar, Indonesia
}

\begin{abstract}
The objective of the study is to determine the efficacy of noni (Morinda citrifolia) extract gel to increase the number of macrophage and angiogenesis in mandibles socket after tooth extraction. In vivo experimental study consist of 32 guinea pigs divided into 4 unpaired groups, first group (control) treated with CMC-Na $2 \%$ gel, the rest (treatment groups) treated, respectively with noni extract gel of 10, 25 and $40 \%$. Animals tooth extraction was performed, followed by gel application twice a day (morning and afternoon) for $1 \mathrm{~min}$ in accordance to the group. Guinea pigs were decapitated on the 5th day, post-extraction's socket and the surrounding bone being removed, fixed and a series of histological examination was conducted. The amount of macrophage cells and angiogenesis were observed and calculated using binocular microscope. Analytic result shows a significant difference in the amount of macrophage and angiogenesis among the treatment group $(\mathrm{p}<0.05)$. Noni extract gel with $10 \%$ concentration was capable to increase the number of macrophage and angiogenesis compared to the concentration of $25,40 \%$ and the control group. It can be concluded that noni extract gel $10 \%$ concentration can accelerate the healing process after tooth extraction of guinea pigs, indicated by an increased number of macrophage and angiogenesis. Flavonoid as an active compound found in noni could increase the number of macrophage as an immuno-stimulant by the activation of T-lymphocytes. Saponin accelerates angiogenesis resulting from changes in balance of activator and plasminogen inhibitor which affects the stimulation of angiogenesis.
\end{abstract}

Key words: Noni extract, Morinda citrifolia, wound healing, accelerate, macrophage, angiogenesis

\section{INTRODUCTION}

Post tooth extraction wound is one of the medium that can allow pathogenic microbes to breed and infect the wound. Human body has a cellular and biochemical ability to repair the integrity and functional capacity of the tissue system resulting from wound, known as wound healing process (Miloro et al., 2004). Post extraction wound will heal easily as body physiologic response but sometimes will develop some complications. There is a need for an action or treatment capable to accelerate wound healing after tooth extraction, particularly among for patients requiring immediate denture placement, braces or implant. Incorrect application of orally intake antibiotic to prevent infection will lead to bacterial resistance against antibiotic. Thus, we are willing to develop topical herb medication as a healing material after tooth extraction. One of the medicinal trees commonly used by the society and known to be very effective is noni (Morinda citrifolia). Noni fruit contains alkaloid compound, flavonoid, glycoside, saponin and triterpenoid (Gunawan et al., 2001). Noni fruit contains primary active compound such as anthraquinon, terpenoid compound, antibacterial substance, damnacanthal (anti cancer substance), polysaccharide, scopoletin, ascorbic acid, beta-carotene, I-arginin, xeronin and proxeronase enzyme from an alkaloid pro-xeronin (Kamiya et al., 2004).

One of inflammatory cells that play an important role in wound healing is macrophage. This cell has the ability to phagocyte more bacteria compared to other polymorphonuclear such as neutrophils before the neutrophil itself become inactive and die. Macrophage has the ability to phagocyte larger particles compared to its size. Macrophage lives for several months even years within the tissue compared to other cell components (Guyton and Hall, 2008).

Corresponding Author: Mochammad Taha Ma'ruf, Department of Oral and Maxillofacial Surgery, Faculty of Dentistry, Denpasar Mahasaraswati University, Indonesia 
The formation of new blood vessels (angiogenesis) is an indicator during wound-healing process (Nugroho, 2005). Tissues require nutrition and oxygen supply to allow better proliferation, facilitated by the angiogenesis process. Angiogenesis occurs in proliferation stage during wound healing about 2 days up to 3 weeks after the injury. This is an important natural process in which during wound healing blood supply is restored to the tissue after injury. The new tissues will receive enough nutrition supply to proliferate (Miloro et al., 2004; Li et al., 2003).

Plenty of studies or researches being carried out on noni as a substance in wound healing after tooth extraction. Research (Sridjaja, 2009) shows that noni extract are capable to increase the number of collagen fibers, after tooth extraction in Dawley rats. Another research (Khoswanto, 2010) shows that noni extract are capable to increase the number of fibroblast after tooth extraction in Dawley rats. In this study we would like to determine the efficacy of noni extract gel to increase the number of macrophage and angiogenesis in mandible socket after tooth extraction.

\section{MATERIALS AND METHODS}

Materials used in this study were noni extract gel, CMC-Na 2\%, Guinea pigs (Cavia cobaya), ketamine, chloroform, alcohol 70\%, Harris Haematoxylin-Eosin (HE) stain, formalin buffer liquid $10 \%$, butcner funnel, Erlenmeyer tube, haemostat and elevator, syringe, tweezers, vacuum rotary evaporator, water bath, binocular microscope (Olympus type CX31).

Noni extract preparation: Noni fruits are thoroughly washed, sliced thinly and dried in room temperature. Later, dried noni was grinded using blender to achieve powder consistency. Noni powder was macerated using ethanol $95 \%$ for 3 days. Result product later been filtered three times using butcner funnel layered by filter study and placed inside Erlenmeyer tubes. The filtrate achieved was steamed with vacuum rotary evaporator and then heated using water bath at $40^{\circ} \mathrm{C}$ until rough extract of noni fruit achieved.

Noni extract gel preparation: Gel preparation achieved by mixing CMC-Na $2 \%$ with sterile aquadest until gel consistency achieved, then added with noni extract until desired concentration achieved.

In vivo study: Based on the research plan, animals ( 32 guinea pigs, 3 months age, body mass of $250-350 \mathrm{~g}$ and healthy) used as the samples. Guinea pigs divided into 4 groups, firstly control group, applied with CMC-Na $2 \%$ gel topically, the rest are treatment group, topically applied with noni extract gel 10, 25 and $40 \%$ each. General anaesthesia was carried out using ketamin $1000 \mathrm{mg} / 10 \mathrm{~mL}$ for $0.3 \mathrm{~mL}$. Tooth extraction done gently using haemostat and elevator in line with tooth socket with equal force to minimize tooth fracture.

Gel was applied to each group for $1 \mathrm{~min}$. twice a day (morning and afternoon). Guinea pigs were decapitated on the 5th day under inhalation method. Post extraction socket and the surrounding bone were removed, cleaned using NaCL solution and fixed using buffer formalin 10\% for $24 \mathrm{~h}$. A series of histological assessments done under Haematoxylin Eosin staining, to observe macrophage cell and new blood vessels (angiogenesis).

Macrophage cells and angiogenesis observation: Observations done by counting the number of macrophage cells which was divided into 5 fragment, then added together and the mean score was calculated. Angiogenesis observation done by counting the number of new blood vessels which was divided into 5 fragment, then added together, then the mean score was calculated. Macrophage and blood vessels observation was done under binocular microscope (Olympus type CX31) with $400 \times$ magnification.

\section{RESULTS AND DISCUSSION}

Number of macrophage: Treatment effect analysis done based on the mean value of macrophage between groups after treatment. The significance analysis result with one way ANOVA is shown in Table 1 (Fig. 1 and 2).

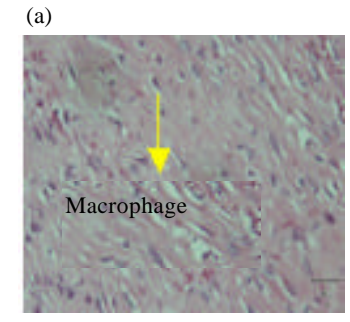

(c)

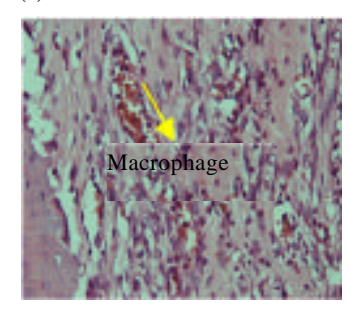

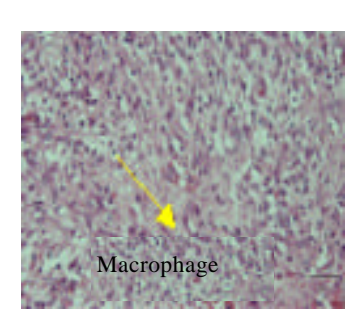

(d)

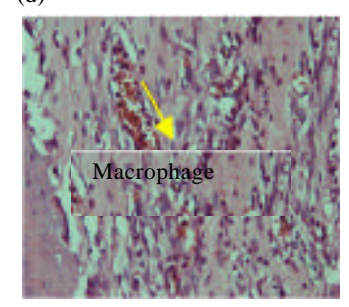

Fig. 1: Macrophage; a) Control group; b) Concentration of $10 \%$; c) Concentration of $25 \%$ and d) Concentration of $40 \%$ 


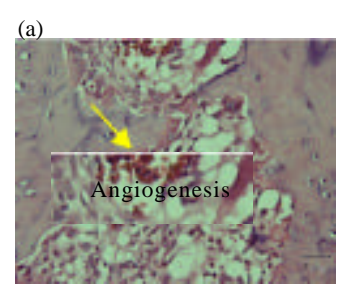

(c)

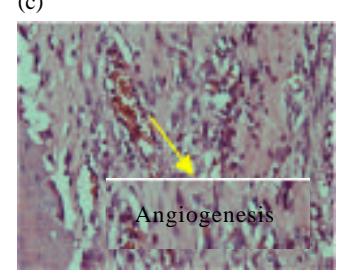

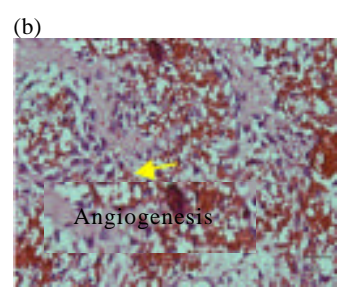

(d)

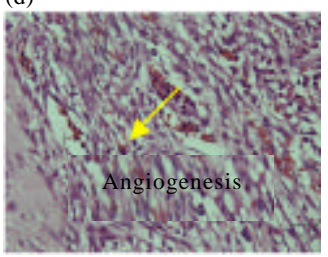

Fig. 2: Angiogenesis; a) Control group; b) Concentration of $10 \%$; c) Concentration of $25 \%$ and d) Concentration of $40 \%$

Table 1 shows the mean value of macrophage in noni extract gel 10\% group is higher compared to the other groups. One way ANOVA test in Table 1 shows that the mean value of macrophage in 4 groups is significantly different $(\mathrm{p}<0.05)$ after treatment. To determine a different group between groups, Least Significant Difference (LSD) test was done (Table 2).

The amount of new blood vessels (angiogenesis): Analysis of treatment effect done based on the mean value of blood vessels between groups after treatment. Significance analysis result done with one way ANOVA, showed in Table 3.

Table 3 shows the mean value of new blood vessels (angiogenesis) in noni extract gel 10\% group (G1) is higher compared to the other groups. One way ANOVA test in Table 3 shows that the mean value of new blood vessels in 4 groups after treatment is significantly different $(\mathrm{p}<0.05)$. To determine a different group between groups, a Least Significant Difference (LSD) test was done. Results are shown in the following Table 4.

Based on the results, there is a higher increase in number of macrophage and new blood vessels in the noni extract gel 10\% group, compared to the noni extract gel 25 and $40 \%$. We could say that noni extract gel can increase the number of macrophage and accelerate angiogenesis process compared to other group without the application of extract gel.

The enhancement on the number of macrophage, most likely caused by flavonoid content in noni fruit which as an immuno-stimulant through the activation of T-lymphocyte. This cells produce Interferon- $\left(\mathrm{FN}^{-\bullet}\right)$, a cytokine produced by the activation of T helper-1 (Th-1 in T-lymphocyte and NK cells). Combination between

\begin{tabular}{|c|c|c|c|}
\hline Groups & Mean value of macrophage & F-value & p-value \\
\hline $\mathrm{C}$ & $33.33 \pm 6.74$ & 33.60 & 0.001 \\
\hline G1 & $84.30 \pm 11.11$ & & \\
\hline $\mathrm{G} 2$ & $65.90 \pm 9.30$ & & \\
\hline G3 & $46.50 \pm 10.02$ & & \\
\hline
\end{tabular}

Table 2: Least Signific ant Difference (LSD) test on number of macrophage \begin{tabular}{l} 
between groups $(n=5)$ \\
\hline
\end{tabular}

\begin{tabular}{llll}
\hline Groups & G1 & G2 & G3 \\
C & $0.001^{*}$ & $0.001^{*}$ & $0.025^{*}$ \\
G1 & & $0.003^{*}$ & $0.002^{*}$ \\
G2 & & & $0.001^{*}$ \\
\hline *Significant values & & &
\end{tabular}

Table 3: Difference in mean value of macrophage between groups ( $n=5$ )

\begin{tabular}{lclc}
\hline Group & Mean value of capillary blood vessels & F-value & p-value \\
\hline C & $4.63 \pm 0.69$ & 12.58 & 0.001 \\
G1 & $7.70 \pm 1.23$ & & \\
G2 & $5.60 \pm 0.46$ & & \\
G3 & $5.33 \pm 1.06$ & & \\
\hline
\end{tabular}

Table 4: Least significant difference test on blood vessels between

\begin{tabular}{llll}
\multicolumn{3}{c}{ groups $(\mathrm{n}=5)$} & \\
\hline Group & $\mathrm{G} 1$ & $\mathrm{G} 2$ & $\mathrm{G} 3$ \\
\hline $\mathrm{C}$ & $0.001^{*}$ & $0.081^{*}$ & $0.199^{*}$ \\
G1 & & $0.001^{*}$ & $0.001^{*}$ \\
G2 & & $0.618^{*}$ \\
*Significant values & &
\end{tabular}

IFN- and the stimulation of pro inflammatory enhance the activation of macrophage. IFN- increases $\mathrm{CD}^{+}$ differentiation to subset Th1 cells and block Th2 cells proliferation. Inhibition of Th2 result to delayed production of IL-4 and IL-5; Lead to delayed allergic and inflammatory reaction by eusinophil. IL-4 stimulates B cells to produce $\mathrm{IgE}$ that will bond with mast cells where IL-5 activates eusinophils.

Stimulated T-lymphocytes during infection will produce a number of limphokines which will draw macrophages to injury area and activate them. The new ones will replace the role of dead macrophage. The number of blood monocytes and macrophage will increase significantly during inflammation. Free macrophage within the tissue will become active during inflammation (Adityatama et al., 2010). Enhancement of macrophage activation could increase the production of cytokines and growth hormones such as VEGF that plays an important role during angiogenesis process. Increased VEGF indicates faster angiogenesis process because VEGF induce mitosis in cultured endothelial cells (Frisca and Sandra, 2009).

Faster angiogenesis might occur because of the saponin content in noni fruits. Saponin has the same effect as b FGF which is important during tube formation of new blood vessels besides, effect of saponin on the balance of plasminogen inhibitor and activator which directly associated with the stimulation of angiogenesis process has been found. Saponin could enhance the expression of mRNA VEGF in blood vessels endothelial cells. Noni fruits contain scopoletin, beside flavonoid and 
saponin as an anti-inflammation and anti allergy (Waha, 2008). Scopoletin can block the production of myeloperoxidase and Prostaglandin E2 (PGE-2) which are mediators for inflammation (Kim et al., 2005). Scopoletin also works as an analgesic due of its ability to bind with serotonin (Bangun and Sarwono, 2002). Xeronin in noni fruits act as a painkiller, this is associated by the ability of xeronin to normalize the proteins within the abnormal cells including brain tissue cells, origins of pain perception (Waha, 2008). Xeronin can resolve the pain after tooth extraction.

Anthraquinone compound in noni fruits plays a role during inhibition bacterial growth. The working mechanism of this compound is by disturbing the peptidoglican composing components in bacterial cell wall, preventing the cell wall to be formed perfectly and this mechanism could lead to cell death. Antibacterial properties of anthraquinone can help the body to prevent infection, fever and bacteria-associated diseases (Wang et al., 2002). These antibacterial properties can prevent infection after tooth extraction.

Terpenoid compound and ascorbic acid in noni fruits could help during organic synthesis process and accelerate body cells healing. Working mechanism of terpenoid compound is similar as phenol compound which is to disturb the transportation process of important ion to the bacterial cells. Trepenoid could bond with fat and carbohydrate which will disturb the permeability of bacterial cell wall. Trepenoid compound is an isometric hydrocarbon compound which can be found in fat or essential oil that very important for the human body. Ascorbic acid in noni fruits is the source of vitamin C. Vitamin $\mathrm{C}$ can delay inflammation, transport radical oxygen to block inflammation process. Noni fruits contain high level of selenium that work as an amazing antioxidant (Waha, 2008). Vitamin C and antioxidant can increase the body immune system and protect from free radicals as well as accelerating wound healing.

\section{CONCLUSION}

Based on the study it can be concluded that noni extract gel 10\% concentrations can accelerate the healing process after tooth extraction of guinea pigs, indicated by an increased number of macrophage and angiogenesis. Flavonoid as an active compound found in noni could increase the number of macrophage as an immuno-stimulant by the activation of T-lymphocytes. Saponin accelerates angiogenesis resulting from changes in balance of activator and plasminogen inhibitor which affects the stimulation of angiogenesis.

\section{REFERENCES}

Adityatama, A.P., E. Arijani and A. Irmawati, 2010. [Increasing number of macrophages on healing wound after post-removal of marmut teeth (Cavia cobaya) due giving meniran extract gel (Phyllanthus niruri lynn) (In Indonesia)]. Oral Biol. Dent. J., 2: 1-4.

Bangun, A.P. and B. Sarwono, 2002. [Benefits and Benefits Mengkudu]. Agromedia Pustaka, Jakarta, Indonesia, (In Indonesia).

Frisca, S.C.T. and F. Sandra, 2009. Angiogenesis: Pathophysiology and clinical applications. JKM., 8: 174-187.

Gunawan, D., W.S. Sudarsono, I.A. Donatus and Purnomo, 2001. [Medicinal plant 2: Research results, properties and use]. Gadjah Mada University, Yogyakarta, Indonesia. (In Indonesia)

Guyton, A.C. and C.E. Hall, 2008. [Textbook of Medical Physiology]. 11th Edn., EGC Medical Book Store, Jakarta, Indonesia,.

Kamiya, K., Y. Tanaka, H. Endang, M. Umar and T. Satake, 2004. Chemical constituent of morinda fruits inhibit cooper-induced low density lipoprotein oxidation. J. Agric. Food Chem., 22: 5843-5848.

Khoswanto, C., 2010. The effect of mengkudu gel (Orinda citrifolia Linn.) in accelerating the ecalation of fibroblast post extraction. Dent. J., 43: 31-34.

Kim, S.W., B.K. Jo, J.H. Jeong, S.U. Choi and Y.I. Hwang, 2005. Induction of extracellular matrix synthesis in normal human fibroblasts by anthraquinone isolated from Morinda citrifolia (Noni) fruit. J. Med. Food, 8: 552-555.

Li, W.W., D. Tsakayannis and V.W. Li, 2003. Angiogenesis: A control point for normal and delayed wound healing. Contemp. Surg., 1: 5-11.

Miloro, M., G.E. Ghali, P. Larsen and P. Waite, 2004. Peterson's Principles of Oral and Maxillofacial Surgery. 2nd Edn., BC Decker Inc, London, England, ISBN: 978-1-55009-234-9, Pages: 1505.

Nugroho, T.S., 2005. [Influence infobtration levobupivacain $0.25 \%$ against quantity of wistar rat angiogenesis in the wound healing incision process days 5. Ph.D Thesis, Diponegoro University, Semarang, Indonesia. (In Indonesia)

Sridjaja, C., 2009. [TESTS of morinda citrifolia linn on the growth of collagen fiber after dental extraction on dawley rast (laboratory experimental)]. Ph.D Thesis, Airlangga University, Surabaya, Indonesia. (In Indonesia)

Waha, M.G., 2008. [Healthy with Noni]. Kesaint Blanc, Jakarta, Indonesia, (In Indonesia).

Wang, M.Y., B.J. West, C.J. Jensen, D. Nowicki, C. Su, A.K. Palu and G. Anderson, 2002. Morinda citrifolia (Noni): A literature review and recent advances in noni research. Acta Pharmacol. Sin., 12: 1127-1141. 